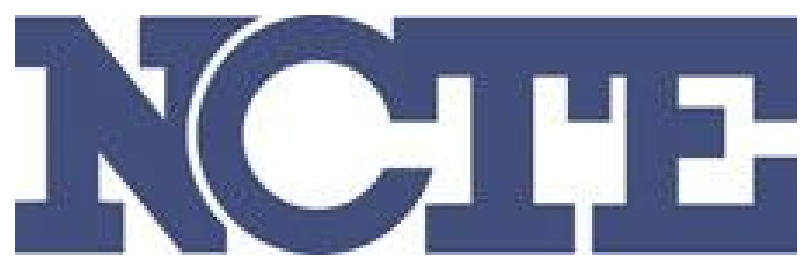

Not All Errors Are Created Equal: Nonacademic Readers in the Professions Respond to Lapses in Usage

Author(s): Maxine Hairston

Source: College English, Vol. 43, No. 8 (Dec., 1981), pp. 794-806

Published by: National Council of Teachers of English

Stable URL: http://www.jstor.org/stable/376679

Accessed: 09-08-2016 16:53 UTC

Your use of the JSTOR archive indicates your acceptance of the Terms \& Conditions of Use, available at

http://about.jstor.org/terms

JSTOR is a not-for-profit service that helps scholars, researchers, and students discover, use, and build upon a wide range of content in a trusted digital archive. We use information technology and tools to increase productivity and facilitate new forms of scholarship. For more information about JSTOR, please contact support@jstor.org.

National Council of Teachers of English is collaborating with JSTOR to digitize, preserve and extend access to College English 


\section{Not All Errors Are Created Equal: Nonacademic Readers in the Professions Respond to Lapses in Usage}

I THINK ENGLISH TEACHERS WHO WANT to be responsible yet realistic about teaching usage and mechanics to today's writing students face a chronic dilemma. What should our priorities be? Is it practical to penalize students for sentence fragments and comma splices when they frequently encounter such constructions in magazines and newspapers? Should we insist that they distinguish between lie and lay or sit and set, and that they use a singular pronoun after everybody? If we do, we risk looking as if we are assuming what Mina Shaughnessy called the "Guarding the Tower" stance, the posture of the protectors of pure English holding off the barbarians who will corrupt the language if we relax our vigilance. We also risk having our students become so anxious about rules that they over-edit while they are trying to write and neglect what is really basic, that is, content and organization.

On the other hand, if we take the attitude that helping students to generate content and organize it in a coherent pattern should be our major goal and that surface features are comparatively unimportant, we open ourselves to attack from that large group of nonacademic readers who are genuinely-even passionately-concerned about good English. They are the administrators and executives and business people who claim that we are not doing our job, that they hire high-school or college graduates who cannot write a readable report or compose a decent letter. They complain that their employees cannot spell or punctuate and that much of the writing they see by professionals is semi-literate. And they imply-or sometimes charge openly-that in their day English teachers were a different breed who had standards and saw to it that no one left their classrooms without being able to write. But however creative their memories may be about their own experience, the fact remains that they do care about standard usage or at least some features of it. The problem is, which ones? Do all mistakes matter? If not, which ones do? Do they have the same priorities for writing that we do?

Maxine Hairston is an associate professor of English at the University of Texas at Austin where she teaches rbetoric and composition courses at all levels and an occasional course in American literature, especially the works of women writers. She is the author of A Contemporary Rhetoric (Houghton Mifflin) and Successful Writing (Norton), a text for advanced composition courses.

College English

Vol. 43, No. $8 \bullet$ December 1981 
This dilemma kept plaguing me as I planned my advanced composition textbook, Successful Writing (New York: Norton, 1981). Presumably most of the students who would be using such a book would be beyond the basic writing stage and ready to give more attention to the conventions of language. Yet they would also be sophisticated enough to realize that professional writers frequently violate handbook rules and their writing does not necessarily suffer. So what advice should I give these students? How careful did they need to be when they got out on the job and were doing working writing? Would it be possible to find out what readers' priorities are? Are there some errors that do not seem to make much difference, but others that matter a great deal?

As far as I know, no one has ever tried to find out how laymen respond to errors in usage, so I decided I would take a poll. I constructed a questionnaire of sixty-five sentences, fewer than I would have liked to use, but as many as I thought my readers would be willing to read and respond to. I included one error in standard English usage in each sentence, and after each sentence I listed three choices: Does not bother me; Bothers me a little; Bothers me a lot. At the end I added an openended question: What is the most annoying feature of the writing that comes across your desk?

To accompany the questionnaire I drafted a carefully phrased letter explaining that I wanted to know what kinds of grammatical errors mattered most in the world of real working writing. I gave these guidelines for responding:

What I would like you to do is read through each sentence rather quickly and mark your response to it. That is, if you encountered the sentence in a report or business letter, would it lower your estimate of the writer, and how much? I do not want to know if you would write it as it appears in the questionnaire, but only if finding the sentence in someone else's writing would bother you.

In the third paragraph I tried to counteract the intimidating effects of taking a quiz from an English professor with these words:

I hope you will be able to respond to these sentences candidly without thinking that a judgmental English professor is looking over your shoulder. I know that English teachers make most people self-conscious about their grammar, but I hope you can set aside that reaction this time and respond to these sentences as naturally and realistically as you would if they occurred in a routine document that you might read in your work. Getting your honest opinion is important to me so that I can make my textbook helpful for both students and teachers.

I had the letters professionally typed and copied, then had a typist fill in the address and salutation for each letter so that they looked individually done; I used first name salutations for people I knew. I numbered the questionnaires in order to identify the responders, and I enclosed a self-addressed and stamped envelope with each one.

I sent the questionnaire to 101 professional people; I included no English teachers. I knew at least slightly eighty-five percent of the people on the list, and I picked the others from among well-known local people. The age of about three-fourths of the people in the sample was over forty; most of them were between fifty and sixty. Three-fourths of them were also men, simply because I know more professional men than women.

My response to the survey was surprisingly high. Eighty-four people returned their questionnaires. Fifty-two of those responding added written comments. Un- 
doubtedly I got such a high rate of response partly because I knew most of the people I was querying, but I believe it was also partly due to people's lively interest in the topic. Many people included in their responses personal comments about the importance to them of good grammar, and for several months after I would meet people at parties or plays and concerts who would ask me about my findings.

The respondents represented sixty-three separate occupations; only seven of them were connected with the academic world, and four of those were administrators. The groups best represented in the sample were business executives (six) and attorneys (seven). Other rather typical occupations were state legislator, computer program designer, architect, travel agency owner, county commissioner, bank president, newspaper columnist, realtor, oil company president, stock broker, federal judge, and a state educational commissioner. (A complete list appears at the end of the article.) Most of the respondents have incomes substantially above average, their work involves significant amounts of reading and writing, and in general they are people whose positions give them status in their communities. Many of them also are in positions to affect other people's lives.

I tallied all the responses to the questionnaire by hand, and I tallied responses from men and women separately. I counted the total responses to each item and tabulated them, classifying the usage error in that sentence as Outrageous, Very Serious, Serious, Moderately Serious, Minor, or Unimportant on the basis of the number of responses in each of the three categories. In some instances, the results were borderline. I had to discard item 8 for a typing error, so I wound up with only sixty-five items.

The first and most striking result that I noticed was that on all but a few sentences, women respondents checked a much higher percentage of "Bothers me a lot" than men did. In many cases, the men respondents split almost evenly between "Bothers me a little" and "Bothers me a lot," but so many women marked the latter that the item fell decisively into the serious error group. For example, fewer than one-fourth of the men objected strongly to leaving the apostrophe out of the contraction "it's," but more than two-thirds of the women did; fewer than one-fourth of the men objected strongly to the omission of a comma before a final free modifier, but three-fourths of the women did. Women also tended to have lists of several "pet peeves" and to make statements like "We should not compromise proper grammar. Wrong should not evolve into right through use and misuse." These findings about women's responses correlate with research in speech and linguistics which shows that women's attitudes toward language are more conservative than men's. ${ }^{1}$

Respondents of both sexes reacted most strongly against errors that were so glaring they might be called "status markers." The most egregious example was "When Mitchell moved, he brung his secretary with him." Seventy-nine out of eighty respondents indicated that the sentence bothered them a lot. Other substandard verb uses such as "When we was in the planning stages," "Calhoun has went," "Jones don't think it's acceptable" also brought overwhelmingly negative responses. Readers very strongly disapproved of two other kinds of errors that might be called "status markers": double negatives and beginning a sentence with an objective pro-

${ }^{1}$ I am indebted to Anne Gere of the University of Washington for calling my attention to this material, notably Robin Lakoff's book, Language and Woman's Place (New York: Harper and Row, 1975). 
noun. For example, "There has never been no one here like that woman," and "Him and Richards were the last ones hired."

Just below this level of what people apparently considered outrageous lapses came a group of mechanical mistakes that seem to be considered very serious. Sentence fragments came close to the top in this group although what Kline and Memering call "broken sentences" 2 brought more protests than a minor sentence like "Cheap labor and low costs. These are two benefits enjoyed by Taiwan firms." But the respondents definitely disapproved of even that sentence. They also strongly disapproved of run-on sentences ("He concentrated on his job he never took vacations"), failure to capitalize proper names (failure to capitalize the words French and German bothered them less), the colloquialism "would of" in place of "would have," lack of subject-verb agreement, and a comma inserted between a verb and its complement (e.g., "Cox cannot predict, that street crime will diminish"). Sentences in which words or phrases were not parallel fell into this "very serious" category, as did faulty adverb forms ("He treats his men bad"). And, to my great surprise, so did a sentence in which "set" was substituted for "sit."

At the next level came what people seem to judge as fairly serious but not major lapses. This group included predication errors ("The policy intimidates hiring"), dangling modifiers, using "I" as an objective pronoun, failing to set off an interrupter like "however" with commas, failure to use commas in a series, tense switching, and using a plural modifier with a singular noun (e.g., "These kind of errors").

People couldn't seem to make up their mind about sentences that used the "everybody-they" construction or its equivalent. I included four sentences that used a plural pronoun with an indefinite singular antecedent; two brought only mild objections, one brought a moderately strong objection, and one a strong objection. I have to conclude that most of the time readers do not regard the construction as a terribly serious error. However, combining "everyone" with the verb "are" brought fifty percent strong negative replies.

A substantial number of errors clustered at a level I would call medium to low. These included not using the possessive form before a gerund, failure to set off an appositive with commas, not using quotation marks appropriately, using "If I was" instead of "If I were," writing "That is her across the street," failure to set off introductory clauses with commas, using "whoever" in a sentence that called for "whomever," using the construction "the situation is . . . when" and not distinguishing between among and between. Sentences with comma splices also fell into this low to moderate group. Of the three sentences in the sample that contained comma splices, none brought more than twenty strong negative responses; of the remaining responses about one-fourth were "doesn't bother me" and half or more were "bothers me a little."

Finally, some deviations from standard usage seem to bother only a very few people. These included using a qualifier before "unique" ("That is the most unique city"), writing "different than" instead of "different from," using a singular verb with "data," using a colon after a linking verb ("Three causes of inflation are:"), and omitting the apostrophe in the contraction "it's."

2"Formal Fragments: The English Minor Sentence," Research in the Teaching of English, 11 [1977], 97110. 
In their written comments many of the respondents once more stressed their strong biases about correct usage. Several focused on specific mechanical problems, mentioning "a plural pronoun following a singular antecedent," "incomplete sentences," "sloppy grammar," "plural verbs with singular nouns," "wrong placement of 'only,", "misuse of commas," "lack of parallelism," and "run-on sentences." Several singled out bad spelling as the most annoying feature they encountered.

But the theme that dominated the written comments was professionals' concern for content; they care even more about clarity and economy than they do about surface features. Some of the remarks were impassioned. One senior vice president of a computer company wrote a long letter saying that the difference between the winners and the also-rans at the top levels of business was the ability to communicate effectively. Another wrote that he hated "literary acrobatics, no matter how grammatical, that tend to obscure meaning." Another wrote that he was bothered most by people's "inability to explain themselves in succinct form." Other complaints were of "long convoluted sentences with needless verbiage," inability to come to the point, overblown language, pomposity, useless words, fake words such as "impact" used as a verb, irrelevant material, and time and again, "lack of clarity." Of the commenters only the bank president seemed serene about it all. He wrote, "I don't let such things bother me." I suppose he feels if one's collateral is sound, grammar doesn't matter.

I recognize the limitations of this investigation. Probably the single factor most likely to skew the study is my being an English professor. I feel certain that many respondents self-consciously looked for the error in each sentence, and there was a certain amount of "trying to do well on the test." I also suspect that any reader is more likely to spot an error when it occurs in an isolated sentence than when it appears in the context of a larger piece of discourse. So I think we must allow for some over-correction in the results and hypothesize that many readers are somewhat less stringent about standard usage than the survey indicates. As Anne Gere and Eugene Smith point out in Attitudes, Language, and Change (Urbana, Ill.: National Council of Teachers of English, 1979), "hypocrisy or inconsistency often intervene between proclamation and practice" (p. 26). I think it is safe to theorize, however, that few people are more stringent about usage than the survey indicates.

The survey also gives information on only a limited number of usage items. Many people suggested other items they would like to have had included-for example, the correct use of "myself." Also, I cannot tell what the effect might have been of my knowing so many people in the sample. Certainly friends were more likely to respond, but I have no idea whether they were more or less candid with me than they would have been with an anonymous pollster. Also, many probably realized that I was using the numbers on the questionnaires to identify respondents, and that may have affected answers.

But in spite of these limitations, I believe the survey has yielded some useful information. On the basis of what I learned I have made changes both in my textbook and in my teaching. For instance, I have never worried a great deal about sentence fragments, asking only, "Do they work?" I have reasoned that since one encounters them so frequently in effective professional writing, probably English teachers were the only ones who worried about them. Certainly I didn't expect the 
professional people in this survey to condemn them so strongly. And they may not condemn them when they are reading magazines or newspapers, but I specifically asked for their response to business writing. In that context, they obviously expect writers to obey the rules, and I suspect that one rule almost everyone remembers from school is a ban on fragments. Apparently many fewer people took the school ban on comma splices to heart, but then I think that they are less readily recognized. I was also surprised to find so many people strongly objecting to the usage "He sent my husband and I" because that kind of construction crops up so frequently in the conversation of educated people. But again I theorize that such lapses may be ignored in conversation but become glaring when they appear in writing. And probably the kind of writing about which we are most intolerant is that which comes across our desks asking us for something.

I was not surprised to have the comments indicate that the qualities in writing that business and professional people value most are clarity and economy. I was surprised, however, at how vehement and specific they were about misspellings, faulty punctuation, and what they unabashedly call "errors." I think it is important for us and for our students to realize that this fairly representative sample of middle-aged and influential Americans has strong conservative views about usage. Although there seem to be some signs of change, and on some usage items the public may be, ahead of the professions, I think that we cannot afford to let students leave our classrooms thinking that surface features of discourse do not matter. They do.

\section{Occupations of Professionals Responding to Usage Survey}

Business executives

Attorneys

Peridontist

State legislator

Insurance adjuster

Hospital group executive

State educational officer

Federal judge

State educational consultant

Radio station owner

Insurance attorney

Accountant

Realtors

Oil company chairman

Speech professor

Physician

State educational commissioner

School superintendent

State senator

Public school attorney

Associate dean of nursing

Lecturer, free lance writer

Oil company president

Lobbyist

University vice president

Newspaper columnist

Radio news commentator

Legislative aide
Anatomy professor

Architect

Travel agency owner

Editor

Dean of continuing education

Nursing professor

State auditor

Free lance writer

Dean of law school

State consultant on arts

Engineer

Designer of computer programs

Insurance executive

Newspaper editor

College president

Chemical engineer

U.S. Congressman

County commissioner

County commissioner's aide

Social workers

Astronomy professor

Public relations executive

Investment counselor

Stock broker

District judge

State administrative aide

Naval officer

Law professor 
Associate dean of law school

Business consultant

Bank president

Talent agency executive
Tax analyst

Management consultant

Chamber of Commerce director

\section{Questionnaire on Conventions of Grammar}

1. Extra copies will be provided for whoever needs them.
Does not bother me:
Bothers me a little:
$\begin{array}{lr}\text { Male } & 19 \\ \text { Female } & 6 \\ \text { Total } & 25\end{array}$
$\begin{array}{ll}\text { M: } & 27 \\ \text { F: } & 13 \\ \text { T: } & 40\end{array}$
Bothers me a lot:
M: 11
F: 3
T: 14

2. Tact not anger is the best tactic in this case.

Does not bother me:

Bothers me a little:
M: 20
F: 6
M: 25
F: 10
$\mathrm{T}: 35$
M: 12
F: 6
$\mathrm{T}: 18$

Bothers me a lot:

3. He concentrated on his job he never took vacations.

Does not bother me:

Bothers me a little:
M: 5
M: 11
F: 0
F: 2
M: 41
F: 20
T: 5
T: 13
$\mathrm{T}: 61$

Bothers me a lot:

4. Wellington said, Trains will just cause the lower classes to move about needlessly.

Does not bother me:
M: 11
F: 0
M: 27
F: 8
T: 35
T: 11
M: 19
F: 14
$\mathrm{T}: 33$

Bothers me a little:

Bothers me a lot:

5. The three men talked between themselves and decided not to fire the auditor.

Does not bother me:
M: 19
F: 4

T: 23
Bothers me a little:
M: 31
F: 7
T: 38

Bothers me a lot:

M: 13

F: 9

T: 22

6. Never reveal your weaknesses to others, they will exploit them.

Does not bother me:

M: 23

F: 3

T: 26
Bothers me a little:
M: 20
F: 11
$\mathrm{T}: 31$

Bothers me a lot:

M: 11

F: 9

) $\mathrm{T}: 20$

7. Everyone who attends will have to pay their own expenses.

Does not bother me:

Bothers me a little:
M: 18
F: 7
M: 24
F: 4
T: 28

8. Murphy is the person we chose to represent us. (Results discarded.)

9. Coventry is the most unique city in England.

Does not bother me:

Bothers me a little:

$\begin{array}{lll}\text { M: } 26 & \text { M: } 20 & \text { M: } 12 \\ \text { F: } 14 & \text { F: } 3 & \text { F: } \\ \text { T: } 40 & \text { T: } 23 & \text { T: } 17\end{array}$

10. People are always impressed by her smooth manner, elegant clothes, and being witty.

Does not bother me:
M: 7
F: $\quad 0$
$\mathrm{T}: 7$

Bothers me a little:

$\begin{array}{lr}\text { M: } & 23 \\ \text { F: } & 4 \\ \text { T: } & 27\end{array}$

Bothers me a lot:

M: 25

F: 18

$\mathrm{T}: 43$ 
11. Almost everyone dislikes her; they say she is careless and insolent.

Does not bother me:

Bothers me a little:

Bothers me a lot:
M: 31
M: 24
M: 3
F: 12
F: 5
F: 6
$\mathrm{T}: 43$
T: 29
T: 9

12. The state's hiring policies intimidate the applications of ambitious people.

Does not bother me:

Bothers me a little:

Bothers me a lot:
M: 14
M: 10
M: 33
F: 1
F: 5
F: 13
T: 15
T: 15
T: 46

13. The small towns are dying. One of the problems being that young people are leaving.

Does not bother me:
M: 6
F: 1
$\mathrm{T}: 7$
$\begin{array}{lr}\text { M: } & 21 \\ \text { F: } & 5 \\ \text { T: } & 26\end{array}$
M: 33
F: 16
$\mathrm{T}: 49$

Bothers me a little:

Bothers me a lot:

14. Having argued all morning, a decision was finally reached.

Does not bother me:

Bothers me a little:
M: 17
M: 17
F: 3
F: 7
T: 24
T: 20
M: 23
F: 12
T: 35

Bothers me a lot:

15. If the regulating agency sets down on the job, everyone will suffer.

Does not bother me:

Bothers me a little:

Bothers me a lot:
M: 4
M: 16
F: 3
M: 39
F: 10
T: 19
F: 9
$\mathrm{T}: 48$

16. The situation is quite different than that of previous years.

Does not bother me:

Bothers me a little:

Bothers me a lot:

$\begin{array}{lll}\text { M: } 24 & \text { M: } 25 & \text { M: } \\ \text { F: } 9 & \text { F: } 7 & \text { F: } 6 \\ \text { T: } 33 & \text { T: } 32 & \text { T: } 13\end{array}$

17. A person who knows french and german will get along well in Switzerland.

Does not bother me:
M: 10
F: $\quad 2$
M: 26
M: 19
F: 5
F: 14
$\mathrm{T}: 12$
T: 31
T: 33

Bothers me a little:

Bothers me a lot:

18. It is late in his term and inflation is worse and no one has a solution.
Does not bother me:
Bothers me a little:
Bothers me a lot:
M: 9
M: 26
F: 2
F: 7
T: 33
M: 7
F: 13
T: 11
T: 20

19. Our companys record is exceptional.
Does not bother me:
Bothers me a little:

$\begin{array}{lr}\text { M: } 13 & \text { M: } 21 \\ \text { F: } 1 & \text { F: } 4 \\ \text { T: } 14 & \text { T: } 25\end{array}$
M: 23
F: 17
$\mathrm{T}: 40$

Bothers me a lot:

20. The President dismissed four cabinet members among them Joseph Califano.

Does not bother me:

$\begin{array}{ll}\mathrm{M}: & 5 \\ \mathrm{~F}: & 0 \\ \mathrm{~T}: & 5\end{array}$

Bothers me a little:

$\begin{array}{lr}\text { M: } & 33 \\ \text { F: } & 7 \\ \text { T: } & 40\end{array}$

Bothers me a lot:

M: 18

F: 15

T: 33 
21. When Mitchell moved, he brung his secretary with him.

Does not bother me:

Bothers me a little:

Bothers me a lot:
M: 0
M: 1
M: 57
F: 0
F: $\quad 0$
F: 22
T: 0
T: 1
T: 79

22. Three causes of inflation are: easy credit, costly oil, and consumer demand.

Does not bother me:

Bothers me a little:

Bothers me a lot:
M: 32
M: 16
F: 10
F: 3
M: 6
F: 6
$\mathrm{T}: 42$
T: 19
T: 12

23. When a person moves every year, one cannot expect them to develop civic pride.

Does not bother me:
M: 8
F: 2
M: 25
F: 7
M: 24
$\mathrm{T}: 10$
$\mathrm{T}: 32$
F: 13
T: 37

Bothers me a little:

Bothers me a lot:

24. We direct our advertising to the young prosperous and sports-minded reader.

Does not bother me:

Bothers me a little:

Bothers me a lot:
M: 10
M: 27
M: 20
F: 2
F: 5
F: 15
T: 12
T: 32
T: 35

25. The worst situation is when the patient ignores warning symptoms.

Does not bother me:

Bothers me a little:

Bothers me a lot:
M: 26
M: 24
M: 8
F: 9
F: 7
F: 6
T: 35
T: 31
T: 14

26. The army moved my husband and I to California last year.

Does not bother me:

Bothers me a little:
M: 2
M: 18
F: 1
F: 3
T: 21
M: 39
F: 18
T: 57

Bothers me a lot:

27. He went through a long battle. A fight against unscrupulous opponents.

Does not bother me:

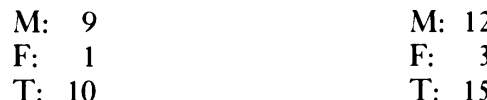

Bothers me a lot:

$\mathrm{T}: 10$

$\mathrm{T}: 15$

M: 38

F: 18

$\mathrm{T}: 56$

28. The lieutenant treated his men bad.

Does not bother me:

Bothers me a little:

Bothers me a lot:
M: 1
M: 17
F: 4
M: 40
F: 0
T: 21
F: 18
T: 58

29. Sanford inquired whether the loan was overdue?

Does not bother me:

Bothers me a little:

Bothers me a lot:
M: 17
M: 21
M: 19
F: 2
F: 8
T: 29
F: 14
T: 33

30. When the time came to pay the filing fee however the candidate withdrew.

Does not bother me:

$\begin{array}{ll}\mathrm{M}: & 7 \\ \mathrm{~F}: & 0 \\ \mathrm{~T}: & 7\end{array}$

Bothers me a little:
M: 13
F: 7
$\mathrm{T}: 20$

Bothers me a lot:

M: 35

F: 15

$\mathrm{T}: 50$ 
31. The data supports her hypothesis.

Does not bother me:
M: 38
F: 12
$\mathrm{T}$ : 50

Bothers me a little:

$\begin{array}{lr}\text { M: } & 16 \\ \text { F: } & 8 \\ \text { T: } & 24\end{array}$
Bothers me a lot:
M: 5
F: 3
T: 8

32. Those are the employees that were honored.

Does not bother me:

Bothers me a little:

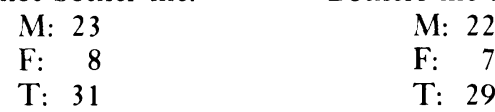

Bothers me a lot:

M: 11

F: 9

$\mathrm{T}: 20$

33. Visitors find it difficult to locate the plant, which affects business.

Does not bother me:

$\begin{array}{ll}\mathrm{M}: & 7 \\ \mathrm{~F}: & 2 \\ \mathrm{~T}: & 9\end{array}$

Bothers me a little:

$\begin{array}{lr}\text { M: } & 26 \\ \text { F: } & 8 \\ \text { T: } & 34\end{array}$

F: 8

T: 34
Bothers me a lot:

M: 24

F: 12

T: 36

34. Him and Richards were the last ones hired.

Does not bother me:
M: 0
F: 0
$\mathrm{T}: 0$

Bothers me a little:

$\begin{array}{ll}\mathrm{M}: & 1 \\ \mathrm{~F}: & 0 \\ \mathrm{~T}: & 1\end{array}$

Bothers me a lot:
M: 56
F: 22
$\mathrm{T}: 78$

35. There has never been no one here like that woman.

Does not bother me:

$\begin{array}{ll}\mathrm{M}: & 0 \\ \mathrm{~F}: & 0 \\ \mathrm{~T}: & 0\end{array}$
Bothers me a little:

$\begin{array}{ll}\mathrm{M}: & 1 \\ \mathrm{~F}: & 0 \\ \mathrm{~T}: & 1\end{array}$

Bothers me a lot:
M: 56
F: 22
T: 78

36. These kind of errors would soon bankrupt a company.

Does not bother me:

Bothers me a little:
M: 8
M: 23
F: 3
F: 4
T: 26
$\begin{array}{ll}\text { M: } & 24 \\ \text { F: } & 16 \\ \text { T: } & 40\end{array}$

Bothers me a lot:

37. My favorite quotation is, "Take what you want and pay for it.

Does not bother me:

Bothers me a little:
M: 20
M: 23
F: 12
F: 0
T: 35
T: 20
M: 13
F: 10
T: 23

Bothers me a lot:

38. The reporter paid attention to officers but ignores enlisted men.

Does not bother me:

Bothers me a little:
M: 5
M: 19
F: 5
$\mathrm{F}: \quad 0$
T: 24
M: 29
F: 17
T: 46

Bothers me a lot:

39. If I was in charge of that campaign, I would be worried about opinion polls.
Does not bother me:
Bothers me a little:
$\begin{array}{lr}\text { M: } & 18 \\ \text { F: } & 5 \\ \text { T: } & 23\end{array}$
M: 17
F: 7
T: 24
M: 19
F: 10
T: 29

Bothers me a lot:

40. If Clemens had picked up that option, his family would of been rich.

Does not bother me:
M: 6
F: 1
T: 7

Bothers me a little:

$\begin{array}{lr}\text { M: } & 14 \\ \text { F: } & 2 \\ \text { T: } & 16\end{array}$
Bothers me a lot:

$\begin{array}{ll}\text { M: } & 36 \\ \text { F: } & 19 \\ \text { T: } & 55\end{array}$ 
41. Its wonderful to have Graham back on the job.

Does not bother me:

Bothers me a little:

Bothers me a lot:

$\begin{array}{lll}\text { M: } 23 & \text { M: } 21 & \text { M: } 10 \\ \text { F: } 3 & \text { F: } 8 & \text { F: } 12 \\ \text { T: } 26 & \text { T: } 29 & \text { T: } 22\end{array}$

42. Calhoun has went after every prize in the university.

Does not bother me:

Bothers me a little:

Bothers me a lot:
M: 1
M: 0
M: 55
F: 0
F: 0
F: 22
T: 1
T: 0
T: 77

43. Next year we expect to send a representative to China (if Peking allows it.

$\begin{array}{ccr}\text { Does not bother me: } & \text { Bothers me a little: } & \text { Bothers me } \\ \text { M: } 9 & \mathrm{M}: 20 & \mathrm{M}: 30 \\ \mathrm{~F}: 0 & \mathrm{~F}: 3 & \mathrm{~F}: 19 \\ \mathrm{~T}: \mathrm{T}: 23 & \mathrm{~T}: 49\end{array}$

44. Cheap labor and low costs. These are two benefits enjoyed by Taiwan-based firms.

Does not bother me:

$\begin{array}{lr}\text { M: } & 13 \\ \text { F: } & 5 \\ \text { T: } & 18\end{array}$
Bothers me a little:

$\begin{array}{lr}\text { M: } & 23 \\ \text { F: } & 5 \\ \text { T: } & 28\end{array}$
Bothers me a lot:

$\begin{array}{ll}\text { M: } & 24 \\ \text { F: } & 12 \\ \text { T: } & 36\end{array}$

45. The difficult part is if the client refused to cooperate.

Does not bother me:

$\begin{array}{ll}\text { M: } & 4 \\ \mathrm{~F}: & 5 \\ \mathrm{~T}: & 9\end{array}$
Bothers me a little:

$\begin{array}{lr}\text { M: } & 20 \\ \text { F: } & 5 \\ \text { T: } & 25\end{array}$

Bothers me a lot:

M: 31

F: 12

$\mathrm{T}: 43$

46. State employees can't hardly expect a raise this year.

Does not bother me:

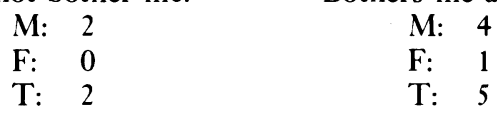
M: 4

T: 5

Bothers me a little:

Bothers me a lot:

$\begin{array}{ll}\text { M: } & 49 \\ \text { F: } & 21 \\ \text { T: } & 70\end{array}$

47. The supervisor has no objections to us leaving.

Does not bother me:
M: 15
F: 4
M: 27
F: 4
T: 19
T: 31

Bothers me a little:

Bothers me a lot:

M: 12

F: 14

T: 26

48. Although the candidate is new to politics she has a good chance of winning.

Does not bother me:
M: 32
F: 10
M: 19
F: 6
$\mathrm{T}: 25$
M: 11
F: 6
T: 17

Bothers me a little:

Bothers me a lot:

49. A convicted felon no matter how good his record may not serve on a grand jury.

Does not bother me:

Bothers me a little:
M: 14
F: 1
M: 27
F: 11
T: 38
T: 15

Bothers me a lot:

M: 14

F: 9

T: 23

50. I was last employed by texas instruments company.

Does not bother me:
M: 3
F: 0
T: 3

Bothers me a little:

M: 15

F: 4

T: 19
Bothers me a lot:

M: 38

F: 17

$\mathrm{T}: 55$ 
51. When leaving college, clothes suddenly become a major problem.

Does not bother me:

Bothers me a little:

Bothers me a lot:
M: 17
M: 18
M: 21
F: 3
F: 5
F: 14
T: 20
T: 23
T: 35

52. Enclosed in his personnel file is his discharge papers and job references.
Does not bother me:
Bothers me a little:

$\begin{array}{ll}\mathrm{M}: & 8 \\ \mathrm{~F}: & 0 \\ \mathrm{~T}: & 8\end{array}$
M: 15
M: 32
F: 2
T: 17
F: 2
T: 34

Bothers me a lot:

53. The president or the vice-president are going to be at the opening ceremonies.

Does not bother me:

$\begin{array}{ll}\text { M: } & 5 \\ \text { F: } & 1 \\ \text { T: } & 6\end{array}$

Bothers me a little:
M: 22
F: 9
$\mathrm{T}: 31$

Bothers me a lot:

M: 30

F: 12

T: 42

54. To me, every person is an individual, and they should be treated with respect.

Does not bother me:

Bothers me a little:
M: 11
M: 28
F: 3
F: 3
T: 31
$\mathrm{T}: 14$
$\begin{array}{ll}M: & 18 \\ \mathrm{~F}: & 16 \\ \mathrm{~T}: & 34\end{array}$

Bothers me a lot:

55. Good policemen require three qualities: courage, tolerance, and dedicated.

Does not bother me:

$\begin{array}{ll}\text { M: } & 5 \\ \text { F: } & 1 \\ \text { T: } & 6\end{array}$
Bothers me a little:

$\begin{array}{ll}\text { M: } & 6 \\ \mathrm{~F}: & 3 \\ \mathrm{~T}: & 9\end{array}$

Bothers me a lot:

$\begin{array}{ll}\text { M: } & 46 \\ \text { F: } & 18 \\ \text { T: } & 64\end{array}$

56. The interruption will not effect my work.

Does not bother me:
M: 20
F: 4
T: 24

Bothers me a little:

$\begin{array}{lr}\text { M: } & 13 \\ \text { F: } & 3 \\ \text { T: } & 16\end{array}$

Bothers me a lot:
M: 26
F: 15
$\mathrm{T}: 41$

57. I have always hoped to work in that field, now I will have the opportunity.

Does not bother me:
M: 12
F: 6
$\mathrm{T}: 18$

Bothers me a little:

$\begin{array}{lr}\text { M: } & 34 \\ \text { F: } & 7 \\ \text { T: } & 41\end{array}$

Bothers me a lot:

M: 10

F: 19

T: 29

58. Senator javits comes from new york.

Does not bother me:
M: 4
F: 0
$\mathrm{T}: 4$

Bothers me a little:
M: 4
F: 2
T: 6

Bothers me a lot:

M: 47

F: 20

T: 67

59. I believe that everyone of them are guilty.

Does not bother me:
M: 11
F: 4
T: 15

Bothers me a little:
M: 21
F: 11
T: 32

Bothers me a lot:
M: 25
F: 7
T: 32

60. That is her across the street.

Does not bother me:
M: 11
F: 2
T: 13

Bothers me a little:
M: 21
F: 10
$\mathrm{T}: 31$

Bothers me a lot:

M: 26

F: 10

T: 36 
61. Cox cannot predict, that street crime will diminish.
Does not bother me:
Bothers me a little:
Bothers me a lot:
$\begin{array}{ll}\text { M: } & 6 \\ \text { F: } & 0 \\ \text { T: } & 6\end{array}$
M: 10
F: 3
M: 42
F: 19
$\mathrm{T}: 13$
T: 61

62. When we was in the planning stages of the project, we underestimated costs.

Does not bother me:

Bothers me a little:

Bothers me a lot:
M: 2
M: 0
F: 0
M: 52
F: 0
T: 0
F: 22
T: 74

63. The union claims it's rights have been violated.

Does not bother me:

Bothers me a little:

Bothers me a lot:

$\begin{array}{lll}\text { M: } 16 & \text { M: } 25 & \text { M: } 14 \\ \text { F: } 1 & \text { F: } 5 & \text { F: } 16 \\ \text { T: } 17 & \text { T: } 30 & \text { T: } 30\end{array}$

64. The company is prepared to raise prices. In spite of administrative warnings.

Does not bother me:

Bothers me a little:

$\begin{array}{lll}\mathrm{M}: 4 & \mathrm{M}: 9 & \mathrm{M}: 44 \\ \mathrm{~F}: 0 & \mathrm{~F}: 2 & \mathrm{~F}: 20 \\ \mathrm{~T}: 4 & \mathrm{~T}: 11 & \mathrm{~T}: 64\end{array}$

65. Jones don't think it is acceptable.

Does not bother me:

Bothers me a little:

Bothers me a lot:
M: 0
M: 4
F: 0
M: 52
F: 1
T: 4
F: 21
$\mathrm{T}: 73$

66. Man is not the only user of tools, apes can also learn to manipulate them.

Does not bother me:

Bothers me a little:

Bothers me a lot:
M: 16
M: 27
F: 11
T: 38
M: 12
F: 8
T: 19
T: 20

67. What is the most annoying feature of writing that comes across your desk? 